\title{
CARACTERIZAÇÃO FÍSICA E FÍSICO- QUÍMICA DE FRUTOS DE PHYSALIS CULTIVADAS NA REGIÃO DE FEIRA DE SANTANA
}

\author{
$\underline{\text { Samuel Pereira da Silva }}^{1}$; Marilza Neves do Nascimento ${ }^{2}$; Natália dos \\ Santos Barroso $^{3}$ e Josandra Souza Teles Fonseca ${ }^{4}$ \\ 1. Graduando em Agronomia, Universidade Estadual de Feira de \\ Santana, e-mail: samuell@doctor.com \\ 2. Orientadora, Departamento Ciências Biológicas, Universidade Estadual de Feira de Santana, e-mail: \\ marilzaagro@hotmail.com \\ 3. Doutoranda, Recursos Genéticos Vegetais Universidade Estadual de Feira de Santana, e-mail: \\ nataliasbarroso@yahoo.com.br \\ 4. Bolsista PIBIC/ FAPESB, Graduanda em Agronomia, Universidade Estadual de Feira de \\ Santana, e-mail: josandrateles@hotmail.com
}

PALAVRAS-CHAVE: Compostos bioativos, semiárido, nutracêutico.

\section{INTRODUÇÃO}

Espécies vegetais, das mais variadas famílias, têm seu uso comprovado na alimentação e na prevenção ou até mesmo no tratamento de doenças. Estas espécies com potencial alimentício e medicinal, atuando de forma conjunta, têm sido denominados alimentos funcionais e/ou nutracêuticos.

O gênero Physalis apresenta um relevante papel nesse contexto, pois em todas as partes da planta encontram-se substâncias com atividade biológica já descrita na literatura, com ênfase para os compostos fenólicos, carotenoides e as fisalinas, aos quais se atribuem várias atividades farmacológicas (Ramadan, 2011).

Por possuir sabor agradável e elevado potencial alimentício e nutricional espécies do gênero têm sido introduzidas em regiões quentes em todo o mundo (Kindscher et al. 2012). Entres as espécies mais conhecidas por seu cultivo e emprego na alimentação humana estão a $P$. ixocarpa Brot e $P$. peruviana L e $P$. angulata devido ao seu elevado potencial medicinal.

Porém as características do ambiente de cultivo têm papel importante em relação ao tamanho, cor, constituintes com propriedades nutricionais, sabor e tempo de maturação dos frutos (Rufato et al., 2008). Além de a variação ser decorrente da condição de cultivo, esta pode ser também devido à variabilidade genéticas entre os acessos utilizados no cultivo. Silva (2012) verificou que o local de coleta e estádio de maturação dos frutos afetou os teores de compostos bioativos e demais características dos frutos, sendo os melhores resultados obtidos em frutos completamente maduros. Estes fatos evidenciam a necessidade de desenvolvimento de estudos voltados para avaliação das modificações nas características dos frutos cultivados em diferentes condições ambientais, para o melhor aproveitamento desse importante recurso.

Assim, este trabalho objetiva verificar as características dos frutos de $P$. angulata, $P$. ixocarpa e $P$. peruviana produzidos nas condições ambientais de Feira de Santana-Ba, através da caracterização física e físico-química dos mesmos em dois estádios finais do desenvolvimento.

\section{METODOLOGIA}

Frutos de Physalis angulata, $P$. ixocarpa e $P$. peruviana, foram produzidos no período de julho a dezembro de 2016 no Horto Florestal da Universidade Estadual de Feira de Santana. 
Os frutos foram coletados nos estádios finais de desenvolvimento, estádio 4 e 5 , conforme determiando por Silva (2013) para P. angulata, Barroso et al., (2017) para $P$. ixocarpa e Sbrussi et al., (2014) para $P$. peruviana. Destes foi determinada a coloração dos cálices e frutos mediante a comparação com a tabela de cores da carta de cores RSH (RHS, 1995). Determinou-se também o peso fresco (g); diâmetros transversais (medida da região mediana) e longitudinais (medida do ápice a base) do fruto ( $\mathrm{mm}$ ).

Após a caracterização, os frutos foram processados, centrifugados e o sobrenadante armazenado em ultrafreezer $\left(-80^{\circ} \mathrm{C}\right)$ para a realização das análises bioquímicas. Determinou-se o teor de sólidos solúveis com o auxílio do refratômetro digital os resultados foram expressos em ${ }^{\circ}$ Brix, os açúcares totais pelo método da antrona (YEMM \& WILLIS, 1954) e açúcares redutores pelo método do dinitrosalicilato (DNS) (MILLER, 1959). As proteínas solúveis foram determinadas colorimetricamente baseando-se na mudança de cor de um reagente (azul brilhante de Coomassie) utilizando-se a albumina de soro bovino pura como padrão (BRADFORD, 1976).

Para as avaliações físicas e bioquímicas dos frutos foram utilizadas 4 repetições de 10 frutos para cada estádio $(\mathrm{n}=40)$. Realizou-se as análises bioquímicas em triplicata. Os resultados foram submetidos a analise de variância e as diferenças entre as médias comparadas pelo teste Tukey, $5 \%$ de probabilidade.

\section{RESULTADOS E DISCUSSÃO}

A figura 1 mostra a coloração dos frutos das espécies estudas em dois estádios de maturação dos frutos. Observa-se que a coloração variou entre as espécies. P. angulata apresentou frutos com coloração verde amarelado com manchas roxo amarronzado em ambos os estádios. P. ixocarpa coloração verde escuro antes de completar a maturação (estádio 4) e verde amarelado quando maduros (estádio 5), e $P$. peruviana passando da coloração amarela antes da maturidade para amarelo alaranjado quando completamente maduro. A identificação da coloração do cálice e frutos para as espécies do gênero é importante, pois o ponto de colheita do fruto é determinante para garantir a sua qualidade, e em Physalis este ponto é determinado pela mudança de coloração do fruto e do cálice que o envolve (RUFATO et al.,2008).
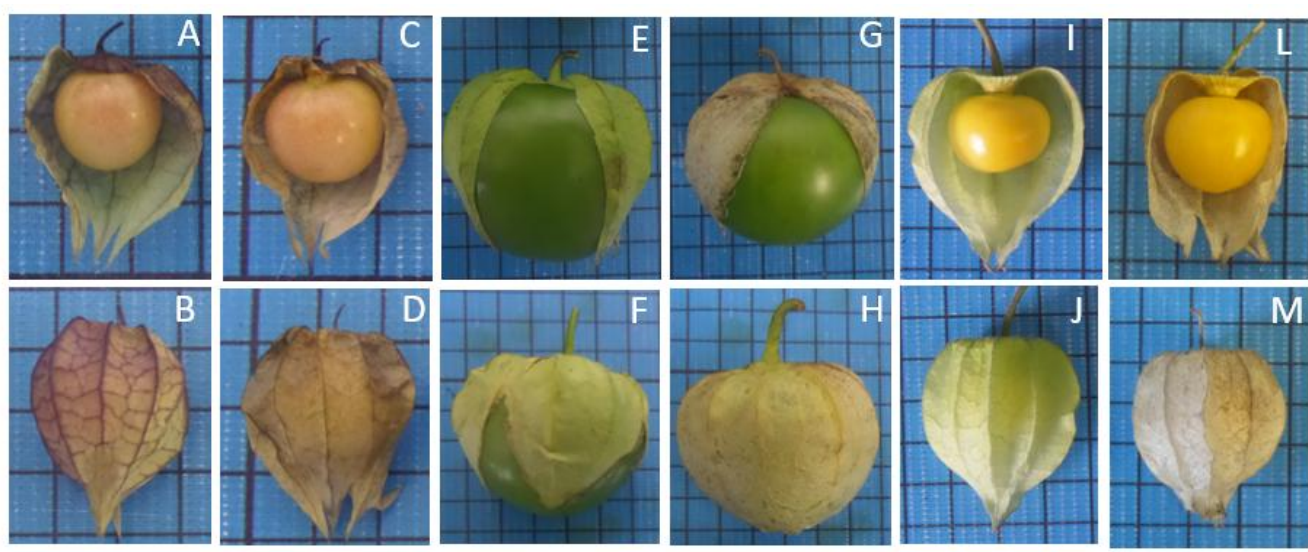

Figura 1: Coloração do cálice e do fruto de $P$. angulata estádio 4 (A;B) e estádio 5 (C;D), P. ixocarpa estádio $4(\mathrm{E} ; \mathrm{F})$, estádio $5(\mathrm{G} ; \mathrm{H})$ e $P$. peruviana estádio $4(\mathrm{~J} ; \mathrm{I})$ e estádio $5(\mathrm{~L}, \mathrm{M})$. Cada quadrado equivale a $1 \mathrm{~cm}^{2}$. Fotos: Natália Barroso. 
A tabela 1 mostra que as maiores médias de comprimento, diâmetro e peso dos frutos são obtidas quando os frutos estão no seu estádio final de maturação para todas as espécies estudadas. Porém, o teor de sólidos solúveis, não apresentou grande variação no valor obtido para estádios avaliados e não diferiram estatisticamente. Incremento no comprimento, diâmetro e peso dos frutos à medida que avança os estádios de maturação também foram observados por Sbrussi et al. (2014), Tanan (2015) e Barroso et al. (2017).

Tabela 1: Comprimento (C), diâmetro (D), peso fresco (PF), sólidos solúveis totais (SST), cor do cálice (CC) e dos frutos (CF), açúcar redutor (AR), açúcares solúveis totais (AST), proteínas solúveis totais (PST) em frutos de Physalis angulata, $P$. ixocarpa e $P$. peruviana em dois estádios de desenvolvimento. UEFS, Feira de Santana, BA, 2017.

\begin{tabular}{|c|c|c|c|c|c|c|c|c|c|}
\hline Estádio & $\mathrm{CC}^{*}$ & $\mathrm{CF}^{*}$ & $\begin{array}{c}\mathrm{C} \\
(\mathrm{mm})\end{array}$ & $\begin{array}{c}\mathrm{D} \\
(\mathrm{mm})\end{array}$ & $\begin{array}{l}\text { PF } \\
(g)\end{array}$ & $\begin{array}{c}\text { SST } \\
\left({ }^{\circ} \text { Brix }\right)\end{array}$ & $\begin{array}{c}\text { AR } \\
\left(\mathrm{g} .100 \mathrm{~g}^{-1}\right)\end{array}$ & $\begin{array}{c}\text { AST } \\
\left(\mathrm{g} .100 \mathrm{~g}^{-1}\right)\end{array}$ & $\begin{array}{c}\text { PT } \\
\left(\mathrm{g} .100 \mathrm{~g}^{-1}\right)\end{array}$ \\
\hline \multicolumn{10}{|c|}{ Physalis angulata } \\
\hline 4 & VA/ RA & $\mathrm{VA} / \mathrm{RA}$ & $12,9 b$ & $13,3 b$ & $1,44 \mathrm{~b}$ & $12,8 \mathrm{a}$ & $0,08 \mathrm{a}$ & $2,6 a$ & $2,4 \mathrm{a}$ \\
\hline 5 & MA & $\mathrm{VA} / \mathrm{RA}$ & $14,5 \mathrm{a}$ & $15,4 \mathrm{a}$ & $2,2 \mathrm{a}$ & $11,8 \mathrm{a}$ & $0,04 \mathrm{~b}$ & $2,9 \mathrm{a}$ & $2,5 \mathrm{a}$ \\
\hline \multicolumn{10}{|c|}{ Physalis ixocarpa } \\
\hline 4 & VA & $\mathrm{VE}$ & $21,5 b$ & $29 b$ & $36,1 b$ & $4,7 \mathrm{a}$ & $0,03 b$ & $0,8 \mathrm{a}$ & $1,2 \mathrm{a}$ \\
\hline 5 & MA & VA & $39,2 \mathrm{a}$ & $37,1 \mathrm{a}$ & $40,4 \mathrm{a}$ & $5,1 \mathrm{a}$ & $0,05 \mathrm{a}$ & $0,8 \mathrm{a}$ & $1,1 \mathrm{a}$ \\
\hline \multicolumn{10}{|c|}{ Physalis peruviana } \\
\hline 4 & VA & A & $10,3 \mathrm{a}$ & $11,8 b$ & $1,6 b$ & $12,8 \mathrm{a}$ & $0,05 b$ & $1,9 b$ & $1,7 \mathrm{a}$ \\
\hline 5 & MA & $\mathrm{AL}$ & $13,5 \mathrm{a}$ & $14 \mathrm{a}$ & $2,3 \mathrm{a}$ & $14 \mathrm{a}$ & $0,10 \mathrm{a}$ & $2,4 \mathrm{a}$ & $1,4 \mathrm{~b}$ \\
\hline
\end{tabular}

* A: Amarelo, AL: Amarelo alaranjado escuro, VE: Verde escuro, VA: verde amarelado, MA: Marrom amarelado claro, RA: Roxo amarronzado escuro. Médias seguidas pela mesma letra na coluna para cada variável analisada não diferem entre si pelo teste de Tukey a 0,05 de probabilidade.

Médias semelhantes, para as variáveis avaliadas, foram observadas por Souza (2015) para frutos maduros de $P$. angulata, $P$. ixocarpa e $P$. peruviana cultivados na região de Feira de Santana. Porem são inferiores aos obtidos em frutos de $P$. angulata coletados em diferentes localidades na Paraíba e de $P$. peruviana cultivadas em Londrina - PR (Silva, 2013; Sbrussi et al., 2014).

O teor de açúcar redutor (AR) foi maior nos frutos antes de atingir a maturidade em $P$. angulata. Já $P$. peruviana e $P$. ixocarpa as maiores médias de AR são observadas em frutos completamente maduros. Os açucares solúveis totais (AST) e proteínas solúveis totais (PT) não difere entre os estádios avaliados tanto nos frutos de $P$. angulata quanto de $P$. ixocarpa. Os frutos maduros de $P$. peruviana apresentaram maior quantidade de AST, porem menor teor de PT.

Os resultados obtidos para R, AST e PT, no presente estudo, são menores do que os obtidos por Tanan (2015) para $P$. angulata e $P$. ixocarpa cultivadas na região de Feira de Santana - BA e por Silva (2013) para $P$. angulata e $P$. peruviana coletadas em diferentes localidades da Paraíba. Esta diferença pode ser devido ao ambiente e condições de desenvolvimento da planta e/ou acesso utilizado nas análises. 


\section{CONSIDERAÇÕES FINAIS}

Na região de Feira de Santana, os frutos de $P$. angulata, $P$. ixocarpa e $P$. peruviana apresentam melhores características no estádio final do desenvolvimento, quando a coloração do cálice e do fruto é completamente alterada.

\section{REFERÊNCIAS}

BARROSO, N. S.; SOUZA, M. O.; RODRIGUES, L. C.S.; PELACANI, C. R. Maturation stages of fruits and physiological seed quality of Physalis ixocarpa Brot. ex hormen. Revista Brasileira de Fruticultura, Jaboticabal, v. 39, n. 3. 2017.

BRADFORD, M.M. A rapid and sensitive method for the quantitation of microgam quantities of protein utilizing the principle of protein-dye binding. Anal. Biochem., 72:24854,1976.

KINDSCHER, K.; LONG, Q.; CORBETT, S.; BOSNAK, K.; LORING, H.; COHEN, M.; TIMMERMANN, B. N. The Ethnobotany and Ethnopharmacology of Wild Tomatillos, Physalis longifolia Nutt., and Related Physalis Species A Review. Economic Botany, p 1-13. 2012.

MILLER, G. L. Use of dinitrosalicilic acid reagent for determination of reducing sugar. Analytical Chemistry, v.31, p.426-428, 1959.

RAMADAN, M. F. Bioactive phytochemicals, nutritional value, and functional properties of cape gooseberry (Physalis peruviana): An overview. Food Research International, v. 44, p.1830-1836, 2011.

RHS.THE ROYAL HORTICULTURAL SOCIETY. colour chart. London: 2001. (4 fan).

RUFATO, L. Aspectos técnicos da cultura da Physalis. Lages: CAV/UDESC; Pelotas:UFPel, 100p, 2008.

SBRUSSI, C.A.G.; ZUCARELI, C.; PRANDO, A.M. E SILVA, B.V.A.B. Maturation stages of fruit development and physiological seed quality in Physalis peruviana. Revista Ciência Agronômica, vol. 45, n. 3, p. 543-549, 2014.

SILVA, P. B. Qualidade, compostos bioativos e atividade antioxidante de frutos de Physalis sp. 2013. 108 f. Dissertação (Mestrado em Ciência e Tecnologia de Alimentos) - Universidade Federal da Paraíba, João Pessoa, 2013.

SOUZA, C. L. M. Armazenamento de sementes e caracterização morfofisiológica de espécies do gênero Physalis. Tese (Doutorado em Recursos Genéticos Vegetais) Universidade Estadual de Feira de Santana, Feira de Santana, BA, Brasil. 2015.

TANAN, T. T. Fenologia e caracterização dos frutos de espécies de Physalis cultivadas no semiárido baiano. 2015. 58 f. Dissertação (Mestrado em Recursos Genéticos Vegetais) - Universidade Estadual de Feira de Santana, Feira de Santana, 2015.

YEMM, E. W.; WILLIS, A. I. The estimation of carbohydrates in plant extracts by anthrone. Biochemical Journal, London, v. 57, p. 508-514, 1954. 